\title{
On the Semiotic Function of Cucurbits
}

\section{By RALF NORRMAN}

In semiotics signs are classified differently according to which school of semiotic thought the classifier sympathizes with, but most taxonomies recognize at least three categories: icons (real likeness between the sign and what it stands for), indices (a causal relationship) and "signs proper" (whose characteristic feature is their arbitrariness-in the Morse-code, for instance, the " $b$ "-sign could just as well stand for " $a$ " if only everyone agreed on the change).

It is of fundamental importance to anyone trying to understand its nature and function to know whether a sign is arbitrary or not.

The literary symbols that authors use are often arbitrary and vary with the culture and period of the text. Indeed "symbolification" is a term used by some linguists to denote the process whereby an author takes any code element in his syntagm and invests it with a special meaning through manipulation of the context. "Symbol" would thus be associated with lability - that half of the dual nature of language which permits us to use language the way the sculptor uses wet clay, i.e. make of it whatever we wish. In this view "symbol" is the opposite of "code" - which is the other role of language, the role in which it functions as a linguistic supermarket where the user of language can choose from the shelves, among stable linguistic elements, the particular one that will suit his communicative need at the moment.

One of the features distinguishing the former half of the nature of language from the latter is the degree of arbitrariness of the sign. If something is used as a sign because of its intrinsic appropriateness for the task this tends to reinforce stability rather than lability, and in this case the relations of the element to the same, or similar-even if contrasting-elements in other texts (its paradigmatic relations, as it were) will be more important than its relations to other elements in the same text (its syntagmatic relations).

Thus, although literary symbols may be fairly arbitrary, there are some cases when the symbols are very stable. One such case is when man uses something from nature to express in metaphors or figurative language (and maybe some forms of totemism) some idea about himself, or somehow define his own position. Thus one finds that plant and animal symbolism is often very stable. "Goose" as a sign of stupidity is used not only because it is agreed that this should be its role in the code; ultimately it is used because geese really are stupid (or, to put it more precisely, because they seem stupid to humans-whether geese, cows and donkeys are stupid from 
an animal point of view is irrelevant). "Goose" as a sign of stupidity is not arbitrary.

If language had been characterized only by its malleability one could also have expected "intelligent" birds to be used as a sign of stupidity, since in principle it should be possible to invest any linguistic element with any meaning through manipulation of the context. But this does not seem to happen-such meanings, if they occur, do not become established. "Goose" as a sign of stupidity is superior because the sign preserves a link with its origin. Every user of the sign can get at its meaning not only through his knowledge of the code (which could have been arbitrary) but also by deducing on his own the meaning of the sign through observations of that part of nature from which it is taken.

In their symbolic use in literature the various plants and animals are thus often given their semiotic role because of intrinsic suitability for it.

This has many consequences. For the student of literature-and I would imagine for the student of the history of religion-it means that chronology loses much of its importance. Research becomes largely ahistorical. If, for instance, the scholar, in studying one culture, notes that a plant from the family Cucurbitaceae occurs in connection with some narrative element depicting abundance, vitality and fertility in a story of the creation, and then finds that the plant occurs in a similar story in a later culture, he need not automatically assume an influence from the earlier culture to the later. In order to understand the semiotic role of the plant it may be much more important to study its physiology (fertility, fast growth, abundant harvest) and its special status in the flora. These signs remain the same provided the nature they refer to remains the same and provided human thought remains essentially the same-which in this context is a reasonable assumption.

In addition to "message" the two central concepts of all semiotic theory are "sender" and "receiver". The process of communication is something collective; sender and receiver share the communicative code. If literature or religion is seen as communication one can concentrate on either the role of the sender (the author, the prophet) or the role of the receiver (the readers, the congregation). Thus one may ponder the question whether literary works are written by the authors or by the readers; whether the author creates something which he forces upon the reader or whether the author is merely "borrowed" to formulate something which is essentially created by the readers. In the same way one may ask whether a prophet forces upon his listeners what he has created or whether the listeners create and the situation then, through some process of selection, filters forth a prophet who formulates individually what was already created collectively.

In plant symbolism, in addition to the role of the sender and the receiver, the message itself plays a very important part. In literary or re- 
ligious texts these elements very often tend to formulate themselves, as it were, because the perfect, the given form of the element is latently in existence, only waiting for the sifting or filtering processes of human thought to bring it forth into materialization.

In this essay, by looking at some aspects of the semiotic role of the plant family Cucurbitaceae (melons, water-melons, cucumbers, pumpkins, gourds, calabashes, squashes, gherkins, marrows etc.). I wish to exemplify four of the ways in which such textual elements "write themselves". The material is taken from a study on the semiotic role of cucurbits in literature which I have undertaken in collaboration with Jon Haarberg. Unfortunately there is no space here to illustrate at length the various connotations of the cucurbits; I shall just have to state them before giving the quote which exemplifies how a literary passage writes itself.

One cluster of cucurbitic connotations is strongly positive. Cucurbitstropical plants, requiring warmth and moisture-are associated with summer, luxury and abundance. Being fertile plants which grow quickly (and die easily) they are a symbol of life and vitality, usually of cyclical life or the life cycle (in contrast to e.g. evergreens which tend to symbolize eternal or enduring life). Closely connected with their role in symbolizing life and fertility are their sexual connotations which are widespread, numerous and far-branching. In particular the sexual connotations abound in associations with femininity.

The cucurbits are in many respects somewhat extreme-they are a typical "record"-species in garden produce (witness the Guinness Book of Records). Thus they acquire in a heightened form the connotations of the place they grow in; they become the epitome of whatever class of concepts they belong to in one or another dimension of their existence. They are the prime produce of a garden; thus they acquire the connotations of gardens in a heightened form, whether this be the scorn of the city-slicker, or the enthusiasm of the back-to-nature romantic. They are usually delicious and thus acquire the symbolic role of the dainty par excellence. They are juicy and thus acquire water connotations.

The cucurbits are even richer in negative connotations than in positive. They are big, immobile (the pumpkin fruit); thus stupid. They are rural, thus anathema to urban people. They grow very quickly and are thus absurd. They are sexy; thus sinful etc.

In our investigation Mr. Haarberg and I found that these connotations are extraordinarily stable. Through the centuries and millennia they remain the same. They also seem to be largely the same in different countries and continents. It is obvious that these signs are very stable. We also noted that although people are usually not consciously aware of it, they unconsciously master the grammar of cucurbits (the semiotic matrix) quite well. Most people realize that a cucurbit often expresses ridicule. An amusing empiric test of people's cucurbitic competence (the extent to which the 
public master a cucurbitic langue) is to mention that Shakespeare calls only one of his characters "pumpkin" (pompeon). People familiar with Shakespeare's plays will almost always immediately-and quite correctlyname Falstaff, who is fat (iconic relationship), absurd like a pumpkin, humorous like a pumpkin, a glutton (cucurbits being a glutton's food); who drinks (wateriness connotations), and is at this stage in the Merry Wives unsuccessfully trying to seduce a woman (sex connotations).

It is obvious that "pumpkin" is maximally suitable, and the idea of suitability, and the gluttony, conveniently bring me to my first example of the ways in which a literary passage writes itself.

\section{Maximal appropriateness}

The principle could be called simply "maximal appropriateness" and the way the selection works is of course quite obvious; when you choose something from nature to illustrate an idea you choose something suitable. If you want an image of hardness you take steel rather than wax. Before steel was known to man he was likely to take bronze. Today the diamond is the epitome of hardness; before it was known man probably used whatever stone was then the hardest when he needed material for figurative language.

Cucurbits are delicious and gluttons and gourmands are fond of delicious food; therefore a good story of a gourmand or glutton should ideally depict him as eating cucurbits. Investigating this we find that cucurbits are a stock item in stories of gourmands and gluttons. The Roman emperor Clodius Albinus, a glutton on the throne, is said to have eaten "melones Ostienses decem" during one single meal, in addition to a fair amount of peaches, grapes, figs and oysters ${ }^{1}$. Of Carinus it is said that he "inter poma et melones natavit" 2 . This weakness became fatal for a Chinese emperor who was so partial to musk-melons that he actually died of over-eating.

The rule that cucurbits occur in connection with gluttons holds irrespective of genre or stylistic level. It is equally to be expected in a children's book by Richard Scarry (where, true enough, it occurs) as in the Historia Augusta (cf. Scriptores).

A perfect form of a story of a glutton should thus have cucurbits as an element, and through some process of selection they often seem to get it.

An observer unfamiliar with the thought that literary passages could write themselves (i.e. determine their own form and shape), and wondering about the technicalities involved in such "writing", might object that the Historia Augusta states that Clodius ate ten melons from Ostia not because this is semiotically appropriate at this point, but because the emperor really did so.

This is the confrontation of a structuralist theory of literature with a

${ }^{1}$ Cf. Scriptores 1, 482-83.

2 Ib. 3, 442-43. 
mimetic. The structuralist would answer that the emperor eating the melons from Ostia may be a necessary but not a sufficient requirement for it to get into the Historia Augusta. Life is immeasurably rich in detail. Therefore literature cannot be indiscriminate imitation but is rather selection, and manipulation and arrangement of the selected material. Literature imitates not life but a refined image of it.

From the numerous things that the emperor can be expected to have done that day the author of the Historia Augusta selects one, his eating ten melons from Ostia, which distils the essence of the emperor's gluttonous nature as the author saw it.

The story creates, syntagmatically, a convincing picture of a glutton. Clodius eats, and he eats a lot. In the choice of a dish for his zenith of gluttony (eating ten of something) the author chooses melons, a fruit which is inherently associated with gluttons. Thereby the author displays his mastery of the paradigm as well as the syntagm. The well-wrought context fits perfectly the well-chosen element he puts in it. This is one of the characteristic signs of a good author. An author who knows the paradigm but has no skill in linking elements together into a well-wrought textual chain produces clichés.

To explain how the cucurbit got into the Historia Augusta one can imagine three models. The first, the "filter model", assumes some process of selection; of all the things the emperor did the author chose the characteristic one; or else the passage, in order to come into existence, had to "wait" for the emperor to do the characteristic thing. The second model could be called the "lie-model". This assumes that no matter what the emperor did in reality, in the Historia Augusta he has to eat ten melons, because this is symbolically so true that it does not matter whether or not it is true literally as well. The third model seeks the explanation in the structure of life itself-being a glutton the emperor did eat ten melons and thus provided the symbol of his gluttony, i.e. lived up to his image.

In our research Mr. Haarberg and I again and again came upon examples where cucurbits were used to epitomize something connected with one of their chief connotations. They were used to symbolize the sexiest, the most absurd, the extremely bathetic, the quickest-growing, the fastest-dying etc., and since they somehow excel in all these areas in reality their being picked for the task to stand as a sign for it in literature, was, in retrospect, not surprising.

\section{Antitheses}

Another principle which leads to literary passages determining their own shape is antithetical juxtaposition, which, of course, is closely related to the principle of maximal appropriateness. Dualistic structuring of reality, one of man's simplest intellectual models, also seems to be one of his dearest. Antonymic or antithetic structuring naturally makes the other half 
of the oppositional pair very predictable once the first is a given. The contrasting element must be different, and as different as possible.

As examples of antithetical structuring I shall take passages where the cucurbit symbolizes life, particularly when this is connected with the wateriness of the fruit. Cucumbers and melons consist chiefly of water, 95-98\%, and wateriness naturally fits in very well with associations with lifewater is a life-giving and life-sustaining factor.

The cucurbit as a symbol of life is frequent and widespread through the ages. Explicit testimony of its role can be found in those occurrences where the juxtaposition of opposites is expressly signalled by an adversity-marker such as e.g. "either-or", and the semiotic significance of its partner is known. The lily for the Greeks was the flower of death. The proverb

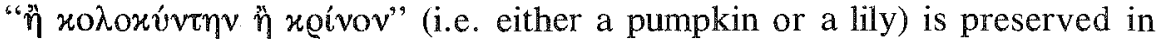
fragments by the comic poets Diphilus and Menander ${ }^{3}$. Since the lily stands for death, the antonymic symbol, the pumpkin, must stand for life.

Deserts and cucurbits, as semiotic elements, are perfect natural antitheses. Deserts are sterile, dry, deathly; cucurbits are fertile, watery, lifegiving. Therefore when authors think antithetically in extremes, the perfect opposite of desert is cucurbit and the perfect opposite of cucurbit desert. The perfect opposition is so obviously neat that it leads to different literary practice in different modes and genres. In those genres where stereotype is cultivated and desired, such as caricature, allegory, etc. the juxtaposition of deserts and cucurbits predictably occurs, whereas realism tries to avoid such perfectly neat constellations and structures. It is therefore only in artistically very poor realist works that one finds the perfect antithetic structuring deserts-cucurbits.

One such work is Henry Rider Haggard's novel King Solomon's Mines (1885). In this work there is hardly any cliché that the reader need wait for in vain. At one stage when the expedition is trekking through an African desert they are in very bad shape: at the limit of thirst and exhaustion. The hot merciless sun beats down on the party, who fear that the end is close at hand. They can see no escape from the hostile desert which is sterile, dry and deathly. Since, in a work of this nature, effect is sought by maximization of the function of the device used (in this case contrast), and the extreme opposite of the desert is the cucurbit-which is fertile, watery and life-giving-the inevitable happens: they discover a patch of melons! "So we sat down under the rocks and groaned, and for one I wished heartily that we had never started on this fool's errand. As we were sitting there I saw Umbopa get up and hobble towards the patch of green, and a few minutes afterwards, to my great astonishment, I perceived that usually very dignified individual dancing and shouting like a maniac, and

3 Cf. Meineke 4, 420 and 331. For a similar antithetic juxtaposition of lily and cucurbit (death and life) cf. e.g. Tennyson's poem "The Princess", L1. 80-91. Ricks, $843 \mathrm{f}$. 
waving something green. Off we all scrambled towards him as fast as our wearied limbs would carry us, hoping that he had found water.

"What is it, Umbopa, son of a fool?" I shouted in Zulu.

"It is food and water, Macumazahn", and again he waved the green thing.

Then I saw what he had found. It was a melon. We had hit upon a patch of wild melons, thousands of them, and dead ripe.

"Melons!" I yelled to Good, who was next me; and another minute his false teeth were fixed in one of them."

After this they kill a bird and by and by get out of the desert. Things improve gradually whereas before the melonpassage they had been growing gradually worse. At the point of juxtaposition (the structural node), the two intrinsically antithetical elements, desert and cucurbit, were employed to heighten the dramatic change in fortune.

What I have tried to stress here is the inevitability of the choice of cucurbits. To supersede and be maximally contrasted with the least watery thing imaginable (desert), there is one suitably watery thing: a melon. The only improvement on this passage would have been for the party to discover water itself, but this possibility was discarded by the author, for several reasons. Melons at this stage, which is the climax of the desert episode, appeal more to the imagination. In the escalation of the thirst-theme, which reappears cyclically, "finding water" is an appropriate element at the beginning, but it cannot be repeated (that would blunt the effect; each new episode must be an escalation from the preceding). To find water now would be an anticlimax. Part of the way the picture of the plight of the party has been created until now is the tacit assumption that they will not find water. Finding water would damage the maximal appropriateness of desert as the driest thing imaginable (a place could hardly be said to be dry if you find water in it!). As it is they find water; yet do not find water.

The same juxtaposition of wilderness and cucurbit is found in the story of an early Christian hermit, who hung a tempting cucumber in front of him $^{5}$. Primarily one may assume that the monk is castigating his gluttonous desire for a fruit which, with its $98 \%$ water content, is a delicacy in the desert. (Although of course it may also be that the monk, living his celibate, sterile life in the sterile wilderness uses a memento which is the symbol of fertility. Thus it is also possible that he is reminding himself of his chastityvow and the cucumber is a visual instrument to conquer his lust. ${ }^{6}$ )

Assuming that cucurbits stand for luxury, fertility and abundance, it is possible to predict the type of literary passages in which they are likely to occur. One such place is Num. 11. The Jews have been trekking through

4 Haggard, $83 \mathrm{f}$.

${ }^{5}$ Cf. Vitae, 767.

6 The idea that cucurbits restrain sexual appetite coexists through the ages with the idea that they induce it. This is the level when the cucurbit has passed into a sign proper. But though interpretations vary arbitrarily (in this case dualistically: does-does not), the kernal, i.e. the connection with sex remains. 
the Sinai Desert for ages and discontent flares up regularly. Throughout Numeri this grumbling recurs as a leit-motif at regular intervals. In Num. 11.5-6 the immediate source of discontent is the diet.

After 40 years the Jews are tired of manna, and being in the sterile Sinai their thoughts antithetically go to the fertile Goshen, where the menu was more varied: "Will no one give us meat? Think of it! In Egypt we had fish for the asking, cucumbers and water-melons, leeks and onions and garlic. Now our throats are parched; there is nothing wherever we look except this manna." (NEB)

Predictably two cucurbits are introduced in the passage. Eating "the bread of the angels" has become monotonous and the Jews recall, as it were, the taste of the two primary dishes for the main course (meat and fish), nice desserts (cucumbers and melons) and spices (leeks, onions and garlic).

It would be next to irrelevant here to inquire into the plants actually grown in Goshen at the time the Jews were there. What is relevant is the situation of the Jews at the moment: hungry, thirsty and bored; and the semiotic position, in the lexicon, of the things they mention-which in each case is antithetical: hungry (meat \& fish), thirsty (cucumbers and water-melons), bored (leeks, onions and garlic). In addition, then, there is the juxtaposition cucurbit-desert (i.e. life-death), expressing the ominousness of their present situation and its difference from their memory of Goshen. The antithesis desert-cucurbit also plays a part in the controversy over the translation, in Jonah IV.6, of the Hebrew word Y Y PיP.

These examples, I hope, sufficiently illustrate the element of predictability, or even inevitability, in the way certain literary passages involving antithesis find their own shape.

\section{Symbols cluster}

Another principle, which like the preceding is also closely related to "maximal appropriateness", is the tendency of symbols to cluster and interrelate, and seek companions which are not only in keeping with the general semiotic drift of the passage in which they occur but paradigmatically congenial.

The principle is one of amount, simply that more is better than less, and the simplest cases are those where an author doubles (or trebles etc.) his symbolism for good measure.

The cucurbit grows very quickly. It is therefore often combined with mushrooms when authors wish to double the symbolism of fast growth. The cucurbits also die easily (none can tolerate frost for instance). Dying as quickly as it grows it has accordingly become the image of short-livedness (an aspect significant e.g. in the Jonah translation-controversy).

The life of some insects is also proverbially short in many languages (Sw. "dagslända" or Eng. "ephemeron"), which explains why gourd in the 
following example should be mentioned with a fly: ${ }^{6} \ldots$ we should have been but as an Ephemeron, Man should have lived the life of a Fly, or a Gourd, the morning should have seen his birth, his life have been the term of a day, and the evening must have provided him of a shroud." 7

An author wishing to double his symbolism and wanting to use the cucurbit in its role as a symbol of stupidity can for instance couple it with a stupid animal, e.g. the sheep, as in Jerome's Novel Notes (1893): "Surely as to a matter of this kind, I, a professed business man, must be able to form a sounder judgment than this poor pumpkin-headed lamb.",8

In these examples two signs were involved. The principle of "symbols cluster" is related to "maximal appropriateness" in that the symbols in this case too, as in the examples from "maximal appropriateness" (which is maybe hierarchically superior-an inclusive concept), have to suit, as to their paradigmatic nature, the slot in the syntagm that they are chosen for. Their additional, specific feature in "symbols cluster" is that they are paradigmatically related to each other as symbols.

This is fairly simple if the symbols are two and their task is to convey one significance (the same). It becomes much more intricate when you increase the number of items and the number of connotations-then the number of relations increases geometrically.

There is a certain numskull story which according to folklorists is spread over large parts of Asia, Europe and the Southern part of the United States. The numskull thinks that a pumpkin is an Ass's egg. He throws it into a bush. A rabbit which has been hiding in the bush is frightened and jumps out. The numskull thinks the egg has broken and the rabbit is the Ass's colt ${ }^{9}$.

In this story practically all the imaginable streams of symbolism converge. The subject is sex; what the numskull is ignorant of are the facts of reproduction. Thus not only is the pumpkin appropriate, with its sexconnotations, but the rabbit is also-rabbits are proverbially fertile. Ignorance of sexual matter is a common theme in this type of humour. But it is not only in the sex aspect that the connection from pumpkin both ways, to the subject and to the animals, is appropriate. The man is stupid; pumpkins are symbols of stupidity and so are asses. The interlacement of relationship in the story is such that every element fits every other.

What I am getting at here is the idea that because of the nature of the case, with two basic ideas involved, sex and stupidity, and three elements of narrative: man, mother-animal and egg/baby-animal, and because of the simple mathematics following from this, there exists latently a perfect form of the story, which tends to force its way, as it were, into existence. Man thinks not in literature, but literature in man.

\footnotetext{
7 Taylor, 21.

8 Jerome, 24.
}

9 Thompson J1772.1 ff. 
An example such as the numskull story is of course interesting to study because the process of the canonization of a text, i.e. its stabilization into a certain form, is slow in orally transmitted literature. There is ample scope for changes towards perfection; for imperfect forms to be discarded; and for a transmitter, who is maybe more clever than the last teller of the story (and masters the semiotic matrix of the elements more fully), to touch into life the element which was waiting for him to take it into the story, where it will remain because it improves the story.

Our findings suggest that even if its importance should not be exaggerated there does seem to exist a tendency for symbols to flock together.

\section{Similar yet different}

If the principle of "maximal appropriateness" was hierarchically superior; and if the first subcategory "antitheses" meant the addition of an abstract relation "difference" plus the introduction of a numbering of the items (two); and if, finally, the second subcategory "symbols cluster" depended on the abstract relation "similarity" (two or more items; one or more connotations) it is to be expected that there should be a category combining the abstract relations of subcategories one and two. Let us call this case simply "Similar yet different".

This, of course, is usually thought of as the basic chart of the metaphor. In "the man is a lion" the man is similar to the lion in his courage, yet different from the lion in that he is not really a lion but a man.

For a passage exemplifying "similar yet different" let me take one where, although cucurbitic symbolism occurs ("punkins" in the passage means important persons-an example of a humorous yet positive meaning of the cucurbit), what I wish to illustrate is expressed in other vegetable symbolism.

"Cabbages" are of extremely low semiotic status. Their low value is sometimes rivalled by that of the cucurbits, but cucurbits are a potentially ambiguous symbol, whereas cabbages are purely negative. The other fruit or vegetable which occurs in the passage, 'pea-nuts', is also very negative. "Mrs. R. had been trying to poke fun at us, behind our backs of course, on the subject of cabbages and pea-nuts. Well, not long after she gave a big ball, and we, being punkins, were of course among the invited. So I went to a clever working jeweller that I knew, and gave him an order to be filled up in all haste from a design of my own, ear-rings imitating peanuts in dead gold, and shirt buttons in green enamel, to be the counterfeit presentment of two cabbages; and Clara and I wore our ornaments at the ball (where they were much admired for their originality), and made a point of bringing them under Mrs. Robinson's notice." 10

In the discussion preceding the story, an Englishman has found it strange

10 Bristed, 216. 
that his American friend confesses his regrets at not having become a wine merchant. The American is militantly self-confident and does not want to give up his identity or be above his origin-his ancestors have made their fortune in peanuts and cabbages. So he creates a paradox, a representation of vegetables of the lowest possible value (peanuts and cabbages) in material of the highest possible value (gold and enamel). The nineteenthcentury American attempt to reconcile the ideas of democracy and social hierarchy was paradoxical. The paradox involved in uniting the two ideas demanded an equally paradoxical symbol, in this case involving a link through colour: nuts-yellow-gold and cabbages-green-enamel.

But with the aid of the paradoxical symbol the American is also signalling to Mrs. R. a message about his similarity and difference: "I may be rich like you, but I am different, and proud of it." Or maybe: "You may think I am different from you, and so I am, but at least I am as rich as you."

To illustrate the role of the principle "similar yet different" in the autogenesis of literary passages let us return to the role of the cucurbit as a symbol of life.

Since the cucurbit symbolizes life the act of cutting a cucurbit sets the human imagination in motion. Thus a number of related symbolic patterns have come into existence. One finds for instance that an eclectic, slightly hedonistic attitude to life and its pleasures (especially love) can be likened to the arbitrary knife of the melon-vendor, as in Alemán's Gvzman de Alfarache: "No falta en Roma bueno, y mas bueno, a menos peligro, y costa, cõ mas gustos, y me nos embaraços: no sè si lo haze, q̃ nuc̃a yo quiero por querer, sino por salpicar, como los de mi tierra: soy cuchillo de melonero, ando picando cantillos, mudando hitos; oy aqui, mañana en Francia; de cosa no me concoxo, ni en alguna permanezco; a mis horas como, y duerno, no suspiro en ausencia, en presencia bozeço, y con esto las muelo." 11

Or else, in a case where the tension of the co-present principles similarity-difference is already felt, if the body of a man is cut, the way a cucurbit would be, one feels there should have been a difference, but, alas, there is not. In Stephen Crane's short story "The Blue Hotel", when the Swede is murdered, the author says the knife cuts his body as it would have a melon. "There was a great tumult, and then was seen a long blade in the hand of the gambler. It shot forward, and a human body, this citadel of virtue, wisdom, power was pierced as easily as if it had been a melon. The Swede fell with a cry of supreme astonishment."12

A melon, like a man, is a prominent example of life, but a melon is insensitive. What seems similar but should nevertheless be different was similar after all.

\footnotetext{
11 Alemán, 250. Cf. Spanish "El melon y el ${ }^{12}$ Gullason, 505 . 
The difference between cutting human flesh and cutting a melon, i.e. the material of two varieties of life, one sensitive and the other insensitive, is a cliche which is utilized particularly in connection with ideas of callousness or cruelty. In a thriller by Edgar Wallace there is a female character who is supposed to be the epitome of cruelty. One of her acts is to slash the hand of an admirer to teach him that his attentions are not welcome. The idea of the following quotation is that to normal people there is a difference between cutting a melon and cutting human flesh, but that to this cruel woman it is all the same. "She is wonderful, really, Mrs Meredith, wonderful! I find myself thinking about her at odd moments, and the more I think the more I am amazed. Lucretia Borgia was a child in arms compared with Jean-poor old Lucretia has been malignated, anyway. There was a woman in the sixteenth century rather like her, and another girl in the early days of New England, who used to denounce witches for the pleasure of seeing them burn, but I can't think of an exact parallel, because Jean gets no pleasure out of hurting people any more than you will get out of cutting that cantaloup. It has just got to be cut, and the fact that you are finally destroying the life of the melon doesn't worry you."

"Have cantaloups life?" She paused, knife in hand, eyeing the fruit with a frown. "No, I don't think I want it. So Jean is a murderess at heart?'13

Consider, for a moment, this quotation and its implications for the idea that art imitates reality! "The realist myth" with which we sometimes delude ourselves claims that art imitates real life. Now it is just not a fact of real life that one's partner in a conversation happens miraculously to have a cantaloupe in her hand any time you need to make a point about cruelty! Neither is it true in life that people make points about cruelty only when their interlocutresses happen to be cutting cantaloupes-though this is much more likely.

It is well known by students of the history of art that art imitates not so much life as other art. A sonnet imitates not only life but above all other sonnets. But, as the Edgar Wallace example demonstrates, even when art does imitate life it is not life in its raw, unordered state, but life as she should have been lived ideally.

In the dual nature of language, the combination of the two contradictory forces of stability and lability, symbols should by definition belong to the lability half. But in the special case of plant symbolism this does not seem to be so. On the contrary, these signs are very stable, which makes possible research organized along dimensions other than chronological; and shifts the emphasis, in the communicative process, from the sender to the receiver(s) and even to the message itself.

Mr. Haarberg and I did not especially seek out religious texts. But when

${ }^{13}$ Wallace, $117 \mathrm{f}$., slashing incident 113. 
we did find religious texts it seemed as if the semiotic role of cucurbits was the same in these as in literary texts in general.

This could suggest that it might be of interest to study certain elements in religious texts and religious systems from a predominantly semiotic point of view, and inquire especially into the question of their intrinsic suitability for their task. At least this would seem to be so with certain cases of plant symbolism.

\section{Bibliography}

Alemán, M., 1661, Primera y segunda parte de Guzman de Alfarache. Madrid. Bristed, C., 1852, The upper ten thousand. New-York.

Gullason, T., 1963, The complete short stories and sketches by Stephen Crane. Garden City.

Haggard, H., 1965, King Solomon's Mines. London.

Jerome, J., 1893, Novel notes. London.

Meineke, A., 1841, Fragmenta Poetarum Comodiae Novae, 4. Berlin.

Ricks, C., 1969, The poems of Tennyson. London.

Taylor, J., 1649, The Great Exemplar of Sanctity and Holy Life, 3. London.

Thompson, S., 1957, Motif-Index of Folk-Literature, 4. Copenhagen.

Scriptores, $1921 \mathrm{f}$ The Scriptores Historiae Augustae, 1, ed. Capps et al.; 3, ed.

T. Page et al. London.

Vitae, 1860, Vitae Patrum. Patrologia Latina, rec. J.-P. Migne, 73. Parisiis.

Wallace, E., 1962, The angel of terror. London. 